\title{
Empirical Examination Of Effects Of Web Assurance Seals On Perceived Level Of Assurance And Price Tolerance With A Focus Being Placed On CPA-Associated Seals
}

Seung Hwan Kim, Ph.D., Indiana University of Pennsylvania, USA

\begin{abstract}
Since the emergence of electronic commerce (e-commerce), the trustworthiness of commercial web sites has been one of the most important, persistent, and interesting issues both in industry and academia. Not surprisingly, web assurance seals have attracted considerable attention among e-commerce vendors due to its potential role as a key factor in the formation of initial trust. However, recent evidence indicates that web assurance seals fail to enhance online purchasing behavior in spite of rosy promises from seal providers. This research examines the mechanism of perceived assurance level formulation through the use of web assurance seal, seeking possible answers to whether Certified Public Accountant (CPA)-associated seals have more effect on the perceived assurance levels than non-CPA-associated seals. As such, the success of web assurance seal is contingent on multiple factors including the attributes of the assurance seal providers, the perceived value of the seal, and the familiarity of the web assurance seal. Overall, this article contributes to both practice and research by shedding light on the largely ignored phenomenon, namely, of web assurance seal failure and by exploring fundamental factors affecting web assurance seal initiative's success.
\end{abstract}

Keywords: E-Commerce; B2C; Online Trust; Website Assurance Seals; CPA

\section{INTRODUCTION}

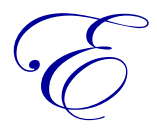

-commerce is growing rapidly despite the dismal economy in recent years (Hu et al., 2010). Although issues of security, privacy, and merchant legitimacy, have been considered one of the top e-commerce concerns and extensively studied, many questions remain to be answered. In an effort to address those issues, e-vendors have adopted web site assurance seals to build consumer trust in their online business practices (e.g., WebTrust, TRUSTe, VeriSign, and BBBOnline). These seals are provided once an online company meets a set of principles and criteria related to system availability, system security, system integrity, and system maintainability, to name a few. All web site assurance seals share the same purpose (i.e., building consumer trust), but they were created by different types of organizations. For instances, TRUSTe was developed by a non-profit organization, and three other web assurance seals (i.e., WebTrust, SysTrust, and BetterWeb) were originated from the accounting profession.

Although it has been more than a decade since the first web assurance seal was introduced in 1997, anecdotal evidence suggests that web assurance seal providers are still struggling to establish themselves in ecommerce industry. The entire assurance market has decreased sharply in terms of number of clients. In contrast, however, CPA-associated web assurance seals have been relatively successful in the market. While literature shows evidence between the use of web assurance seals and positive consumer behavior, the potential role of seal vendor 
origination needs to be examined for empirical validity to investigate the missing link among web assurance seal initiative, its success, and contextual conditions. As such, the primary focus in this study is on the association between the awareness of CPA-associated web assurance seals and their value, compared with non-CPA-associated web assurance seals. In addition, the influence of the generalized perception of assurance on price tolerance is investigated to assess the value of CPA-associated web assurance seals.

\section{LITERATURE REVIEW}

With the spread of e-commerce, online trust has been increasingly researched in the IS (information systems) domain. Researchers have sought to establish a reliable construct and definition of trust, devise instruments for its measurement, and empirically test competing models for trust formation in the context of ecommerce (Gefen et al., 2003). Although it is not surprising that many studies in online trust resort to existing works on trust in offline setting, one should also note inherent differences between two notions. The technology and its host organization are the proper objects of trust in an online environment whereas a person or an organization is the primary object of offline trust (Shankar et al., 2002).

Much of the research into online trust focuses on initial trust formation, with emphasis on the antecedents of initial trust. The notion of ongoing trust in an e-commerce setting is acknowledged but not explicitly explored. Several characterizations have been advanced for the formation of initial trust. Initial trust has been characterized as the trust that appears at the beginning of the relationship and is a consequence of the level of credibility, integrity, and benevolence of the partners. McKnight et al. (2002) adapt this to an e-commerce context arguing that the period during which a consumer visits and explores a vendor's web site for the first time is part of initial trust formation. Institution based trust, which addresses one's sense of security from guarantees, safety nets, or other impersonal structures such as web assurance seals, is acknowledged as a key factor in the formation of initial trust (Kim \& Prabhakar, 2004).

The notion of web assurance seals emerged as a response to the necessity of initial trust formulation. Since TRUSTe, the first web assurance seal in 1997, many other forms of web assurance seals have been introduced to the market. Some of them (e.g., BBBOnline Reliability, BBBOnline Privacy, and VeriSign Secured) were designed to address more specific concerns of assurance (e.g., transaction security assurance, transaction-integrity assurance and consumer privacy assurance among others). Studies explored the use of web assurance seals as an institutional cue to engender consumer trust (Hu et al., 2010). In this context, displaying web assurance seals results in higher expectation of product quality (Houston and Taylor, 1999) and greater intent to purchase online especially when the particular web assurance seal is familiar to customers (Kovar et al., 2000; Odom et al., 2002). From extant literature, however, it is evident that multiple factors influence the relationship between the use of web assurance seal and consumer behavior. The influential factors include the attributes of the assurance seal providers (Kaplan and Nieschwietz, 2003), the perceived value of the seal (Wakefield et al., 2004), comfort with the Internet and information risk (Maudin and Arunachalam, 2002), and the familiarity of the web assurance seal (Odom et al., 2002), to cite a few.

While evidence of association between the use of web assurance seals and positive consumer behavior is apparent, conflicting views also exist, suggesting that the use of web assurance seals is losing influence on online consumers' shopping behavior (Bellman et al., 1999) and that privacy concerns do not significantly affect online behavior (Berendt et al., 2005). These views posit that online users are more concerned about convenience, cost, and content, and willing to trade-off security measures for other web features partly because online users are generally unaware of what a site must do to acquire a seal, or even what a genuine seal actually looks like (Moores, 2005). As anecdotal evidence, the number of clients in web assurance seal market fell significantly, indeed (Jamal et al., 2003).

After all, do online consumers have less need for web assurance seals? Or, is there any missing link between the use of web assurance seals and initial trust which leads to positive consumer behavior online? Although previous studies have made important contributions toward our understanding of whether web assurance seals enhance consumers' online trust, their findings are inconsistent to answer these questions. 


\section{HYPOTHESES DEVELOPMENT AND METHODOLOGY}

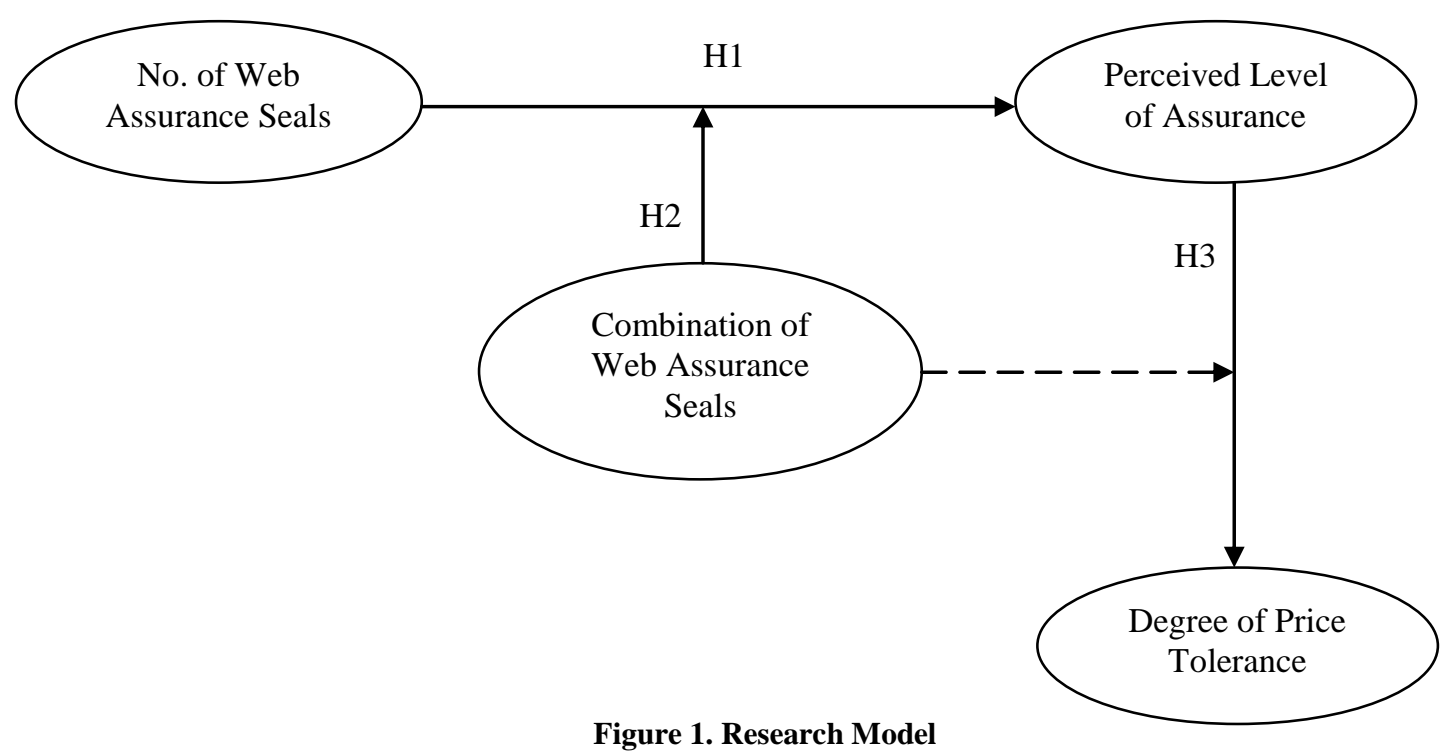

Based on the foregoing discussions of previous online trust and e-commerce literature, the research model is shown in Figure 1. It depicts the four main constructs of this study: number of web assurance seals, combination of web assurance seals, perceived level of assurance, and the degree of price tolerance.

\section{Hypotheses Development}

Interestingly, more and more web sites adopt more than one assurance seal, bearing additional costs to be certified for multiple assurance seals. It needs to be scrutinized if multiple assurance seals produce higher levels of perceived assurance among online consumers. A hypothesis below is designed to investigate such phenomenon.

Hypothesis 1 (H1): As the number of non-CPA-associated web assurance seals displayed on a web site increases, online consumers' perceived level of assurance on the web site also increases. CPA-associated web assurance seals try to distinguish themselves from non-CPA-associated seals by taking advantage of high recognition of accounting profession in the general public for attestation and consulting services. However, does the accounting association of an assurance seal really help in generating assurance-perception? To investigate this, the following is hypothesized:

Hypothesis 2 (H2); When multiple web assurance seals are displayed on a web site, a combination of web assurance seals that includes both CPA and non-CPA-associated web assurance seal(s) produces significantly higher level of perceived assurance than a combination of web assurance seals consisting of only non-CPA-associated web assurance seals. Another interesting subject for investigation is whether an increased level of perceived assurance can result in making a financially positive difference for e-commerce vendors. Hence, the following is proposed for further investigation.

Hypothesis 3 (H3); The higher level of assurance online consumers perceive, the higher price the online consumers are willing to pay. 


\section{Methodology}

\section{Web Assurance Seals}

The web assurance seals that were used in the study were:

\begin{tabular}{|l|l|}
\hline CPA-associated web assurance seals & WebTrust, SysTrust, and BetterWeb \\
\hline Non-CPA-associated web assurance seals & $\begin{array}{l}\text { TRUSTe, BBBOnline Privacy, BBBOnline Reliability, Good } \\
\text { Housekeeping, VeriSign, and GeoTrust }\end{array}$ \\
\hline
\end{tabular}

WebTrust and SysTrust are products that were developed jointly by the American Institute of Certified Public Accountants (AICPA) and the Canadian Institute of Chartered Accountants (CICA). BetterWeb is a product of PriceWaterhouseCoopers, one of the major US-based international accounting firms. TRUSTe, BBBOnline Privacy, and BBBOnline Reliability were created by non-accounting and non-profit organizations; on the other hand, Good Housekeeping, VeriSign, and GeoTrust were initiated by non-accounting and for-profit organizations. GeoTrust has been owned by VeriSign since September, 2006.

\section{Subjects}

The research was administered to more than 300 undergraduate and graduate students in a large midwestern state university. In an effort to increase generalizability, the subjects were sought from every college unit of the university.

\section{Survey Medium and Administration}

Paper surveys were utilized. To encourage active participation in the survey, questionnaires were distributed and completed in class. Subjects were asked questions about a text book purchase at a newly developed online vendor's site. This represented a condition of low product risk with high vendor risk. In addition to the questions to test the hypotheses, demographic information of the surveyed subjects was gathered. Although there are four possible combinations: high-risk product with high-risk vendor, high-risk product with low-risk vendor, low-risk product with high-risk vendor, and low-risk product with low-risk vendor. Low-risk product with high-risk vendor was chosen for the current study because, technically speaking, all the web assurance seals available on the market provide some level of assurance on their clients' web sites but do not provide any kinds of assurance on the products or services of the client companies.

\section{Instrument Development}

When developing instruments, manipulation checks were constructed by rephrasing key instruments with a different response scale. The survey instrument was pilot-tested on twelve randomly selected graduate students. The data of the pilot were subsequently checked for the understandability of instruments and accuracy of measurement scales. In turn, feedback and suggestions were accommodated in revising the following versions of instruments.

\section{Conceptual Framework of Hypotheses Testing}

\section{Test of Hypothesis 1 (No. of non-CPA seals to level of assurance)}

The test started by displaying one non-CPA-associated seal at random and continued by adding a random seal of the remaining non-CPA-associated seals, one at a time. Then, the changing level of perceived assurance was measured in a simulation situation in which a subject pretended to purchase a low-risk product at a high-risk online company that displayed the non-CPA-associated seal(s) on its web site.

There are a total of 63 possible combinations from a set of six different seals, as shown below: 


$$
\begin{aligned}
& C(6,1)+C(6,2)+C(6,3)+C(6,4)+C(6,5)+C(6,6)=63 \\
& \because C(n, k)=\frac{n !}{k !(n-k) !}
\end{aligned}
$$

In these 63 combinations, there is an unbalance regarding the number of times each seal exposed to subjects among component sets of combinations. For example, each seal in the component combination set $C(6,1)$ is exposed to only one subject, while each seal in the component combination set $C(6,3)$ is exposed to ten subjects. To compensate for the unbalance and make the number of each seal exposed to subjects equal across the component sets of combinations, each component set of combinations was multiplied as follows:

$C(6,1) \times 20+C(6,2) \times 4+C(6,3) \times 2+C(6,4) \times 2+C(6,5) \times 4+C(6,6) \times 20=294$

This resulted in each seal being exposed equally to 20 subjects in every component set of combinations. In this test, a 100-percentile scale was used to measure perceived level of assurance for each combination.

Test of Hypothesis 2 (All non-CPA seals to mixed seals on level of assurance)

Subjects were asked to tell which of the nine assurance seals were CPA-associated seals; immediately after that, the subjects were told which ones were CPA-associated seals with brief explanations of their backgrounds of accounting profession. At this time, all the other six non-CPA-associated seals were explained briefly in a very similar fashion and length. It was measured and corrected at the pilot study whether CPA-associated seals seemed advertised over non-CPA-associated seals or vice versa.

Then, three comparisons were made between non-CPA-only seal groups and coexisting seal groups. The first comparison was between groups of seals that consisted of two non-CPA seals and groups of seals that consisted of one non-CPA seal and one CPA seal. The second comparison was between groups of seals that consisted of four non-CPA seals and groups of seals that consisted of two non-CPA seals and two CPA seals. The third comparison was between groups of seals that consisted of six non-CPA seals and groups of seals that consisted of three nonCPA seals and three CPA seals.

To do the first comparison, a total of $18\left({ }_{6} C_{1} \times{ }_{3} C_{1}\right)$ possible groups of seals that consisted of one non-CPA seal and one CPA seal were composed. Next, a random half (9) of the 18 groups were combined with a random nine of $\left.30{ }_{6} C_{2} \times 2\right)$ groups of seals that consisted of two non-CPA only seals for a within-subject comparison. Then, the other half (9) of the 18 groups of seals were combined with groups of seals outside of the 30 groups of seals for a between-subject comparison. This process was repeated one more time. The second and third comparisons went the same way as the first comparison.

Throughout the tests of the first and second hypotheses, around three combinations of assurance seals were tested per subject in the same simulation situation as that in H1. In this test, a 100-percentile measurement scale was used to gauge level of perceived assurance.

Test of Hypothesis 3 (The higher level of assurance to the higher price)

Subjects were asked what maximum price they were willing to pay, as they perceived the higher level of assurance on a web site. The lowest online price was assumed $\$ 50$ for a product each subject was interested in.

\section{DATA COLLECTION AND RESULTS OF TESTS OF HYPOTHESES}

\section{Data Collection}

Three hundred and eight copies of questionnaires were prepared for data collection. In the questionnaires, the web assurance seals were printed in actual size and color in order to maintain the visual effect that each assurance seal had. It took 10 to 15 minutes to administer one set of survey in a class, depending upon the size of the class. 


\section{Division of Questionnaire}

The questionnaire for the study was divided into two parts. The first part of the questionnaire contained questions for demographic information, and asked the question of whether the subject could distinguish between CPA-seals and non-CPA seals. At the beginning of the second part of the survey, the answer for the last question of the first part was provided. The rest of the second part of the questionnaire was filled with simulation questions to test hypotheses 1 through 3 . When data were being collected using the two divided parts of the survey, each part of the questionnaire was distributed and returned in a sequential manner; after the first part was filled out and turned in, the second part was handed out and completed.

\section{When Data Collected}

Out of the 308 questionnaire-sets administered, 302 questionnaire-sets (98 percent response rate) were returned and entered into data analysis. The data were collected over a 41-day period (from February 20, 2008 to March 31, 2008).

\section{Atmosphere of Data Collection}

In every class data were sought in, the instructor for the class allotted his/her class time for the students to participate in the survey. Before questionnaires were distributed to the students, every instructor made a strong encouraging statement and stayed throughout the data-collection time. Except for two classes, the survey was administered at the beginning of class. In one of the two classes where data were collected at the end of class, extra points were set up as an incentive to induce a high rate of participation in the survey. In the other class, the instructor closed his lecture early enough in order to allow sufficient time for the students to complete the survey during the class time.

Contrary to the positive facets of a highly encouraging atmosphere in which data were collected, it could be speculated that the experimental conditions in which data were captured might not be controlled to be the same for all classes. There seemed no significant conditional differences observed among the classes, whether or not there was an incentive for the participation. During the data-screening phase, this was purposely checked and confirmed. Grounded on this observation, it was presumed that there were not extraneous variables that might affect the relationships in the study.

\section{Data Screening}

There were 10 cases in which Part 1 of the survey had one question unanswered, whereas there were no cases that had any question unanswered for Part 2 of the survey. Considering the number of these cases to be insignificant, the unanswered questions were answered with the choices that were the most likely, comparing the answer-patterns of those cases with the rest of the cases in their respective part.

\section{Demographic Information}

Among the 302 collected and used questionnaire-sets, 176 were completed by male students (58.3 percent), and 126 by female (41.7 percent). Other basic demographic information of the subjects is provided in Table 1 and Table 2.

Table 1: Age

\begin{tabular}{|c|c|c|c|}
\hline Range & Frequency & Percent & Cumulative Percent \\
\hline-20 & 88 & 29.1 & 29.1 \\
$21-25$ & 168 & 55.6 & 84.7 \\
$26-30$ & 33 & 11.0 & 95.7 \\
$31-35$ & 6 & 2.0 & 97.7 \\
$36-$ & 7 & 2.3 & 100 \\
\hline Total & $\mathbf{3 0 2}$ & $\mathbf{1 0 0}$ & \\
\hline
\end{tabular}


Table 2: Academic Level

\begin{tabular}{|l|c|c|c|}
\hline \multicolumn{1}{|c|}{ Academic Level } & Frequency & Percent & Cumulative Percent \\
\hline Freshman & 27 & 8.9 & 8.9 \\
Sophomore & 24 & 7.9 & 51.8 \\
Junior & 104 & 34.4 & 78.0 \\
Senior & 81 & 26.8 & 99.3 \\
Master's student & 64 & 21.2 & 100.0 \\
Doctoral Coursework & 2 & .7 & \\
\hline Total & $\mathbf{3 0 2}$ & $\mathbf{1 0 0 . 0}$ & \\
\hline
\end{tabular}

\section{Test of Hypothesis 1 (No. of non-CPA seals to level of assurance)}

Regression analysis was used to test H1. Ideally, regression analysis works best when variables are on a continuous spectrum. In this sub-model for $\mathrm{H} 1$, the dependent variable (perceived-level-of assurance) was a continuous variable, but the independent variable (no.-of-assurance-seals) was a ratio variable. Values of ratio variables are spaced equally on a measurement scale.

Despite the fact that the variable, no.-of-assurance-seals, was not a continuous variable, the regression approach was applicable to the sub-model without seriously distorted results, assuming the no.-of-assurance-seals was on a continuous measurement scale. With that said, it should still be acknowledged that regression analysis in this sub-model would not be as precise as it could be when all the variables were continuous.

The linear relationship between number-of-assurance-seals and level-of-assurance was significant at a .05 significance level $(p<.05)$. The slope of the regression line was significantly different from zero, but marginally. $R^{2}$ was .019 (1.9 percent) in Table 3. So, the number-of-assurance-seals $(t=2.334)$ was a significant but a marginal predictor of assurance level.

\section{Level-of-Assurance $=\mathbf{5 2 . 0 9 2}+(\mathbf{2 . 8 1 1}) \times($ No.-of-Seals $)+$ error}

Table 3: Summary of Analysis (H1)

\begin{tabular}{|c|c|c|c|}
\hline $\mathbf{R}$ & R Square & F & Significance \\
\hline .137 & .019 & 5.449 & .020 \\
\hline
\end{tabular}

\section{Test of Hypothesis 2 (All non-CPA seals to mixed seals on level of assurance)}

Initially, the relationship between number-of-assurance-seals and level-of-assurance was planned to be tested over the moderator variable, i.e., combination-of-assurance-seals. As illustrated in the test of H1 above, however, the relationship between number-of-seals and assurance-level was not significant from a practical standpoint; only 1.9 percent of variance in assurance-level was explained by the variance in number-of-seals. Even though the relationship was statistically significant, it did not bear practical significance. For this reason, a test of moderation was not performed to test the hypothesis.

As an alternative method to statistical analysis, a descriptive approach was utilized to determine the difference between CPA-associated seals and non-CPA-associated seals in generating cognitive assurance among subjects. Table 4 depicts the difference in assurance level perceived by subjects, comparing 2, 4, and 6 non-CPA seals' cases with 2, 4, and 6 seals' cases with the half-and-half combination of CPA-associated and non-CPAassociated seals.

Table 4: Descriptive Comparison (H2)

\begin{tabular}{|c|c|c|c|}
\hline No. of Seals & Non-CPA Seals Only & CPA \& Non-CPA Seals & Difference \\
\hline 2 & 60 & 70 & 10 \\
\hline 4 & 66 & 70 & 4 \\
\hline 6 & 68 & 76 & 8 \\
\hline
\end{tabular}

\footnotetext{
* Values of perceived level-of-assurance were taken by averaging.
} 
The differences between the two groups seemed significant overall. This table supported the idea that CPAassociated seals in the case of multiple seals display had a positive effect on perceptional level of assurance.

\section{Test of Hypothesis 3 (The higher level of assurance to the higher price)}

Correlation analysis was used to test H3. It was selected based on data collection method where one group of subjects were asked to measure the assurance level they perceived when they looked at set of assurance seals while the other group of subjects measured maximum price they were willing to pay looking at the same set of assurance seals. Before correlation analysis was run on the data, a scatter gram on level-of-assurance vs. maximumprice was run and examined. Three entries of maximum-price that were equal to or greater than $\$ 100$ were deemed outliers and excluded from the analysis. The Pearson correlation $(r)$ for the H3 sub-model was .026 in Table 5 and Table 6, which was very low. Similarly, taking $R^{2}$ (.001 or .1 percent) in Table 7 into consideration from a regression perspective, it was clear that there was almost no relation between level-of-assurance and maximumprice. H3 was not supported.

Table 5: Descriptive Statistics (H3)

\begin{tabular}{|l|c|c|c|c|c|}
\hline & No. of Data & Minimum & Maximum & Mean & $\begin{array}{c}\text { Standard } \\
\text { Deviation }\end{array}$ \\
\hline Level of Assurance & 169 & .00 & 100.00 & 59.5858 & 32.54274 \\
Maximum Price & 176 & 5.00 & 99.00 & 48.6875 & 13.75122 \\
Valid Listwise Data & 169 & & & & \\
\hline
\end{tabular}

Table 6: Correlations (H3) (Valid Listwise Data=169)

\begin{tabular}{|l|c|c|}
\hline & Level of Assurance & Maximum Price \\
\hline Level of Assurance & 1 & .026 \\
Significance & & .370 \\
\hline Maximum Price & .026 & 1 \\
Significance & .370 & \\
\hline
\end{tabular}

* Pearson correlation

**Significance at 1-tailed

Table 7: Model Summary (H3)

\begin{tabular}{|c|c|c|c|}
\hline $\mathbf{R}$ & R Square & Adjusted R Square & Std. Error of the Estimate \\
\hline 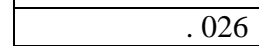 & .001 & -.005 & 13.87171 \\
\hline
\end{tabular}

\section{Additional Test}

Question; Can CPA-seals help 'fetch more money' than non-CPA-only seals?

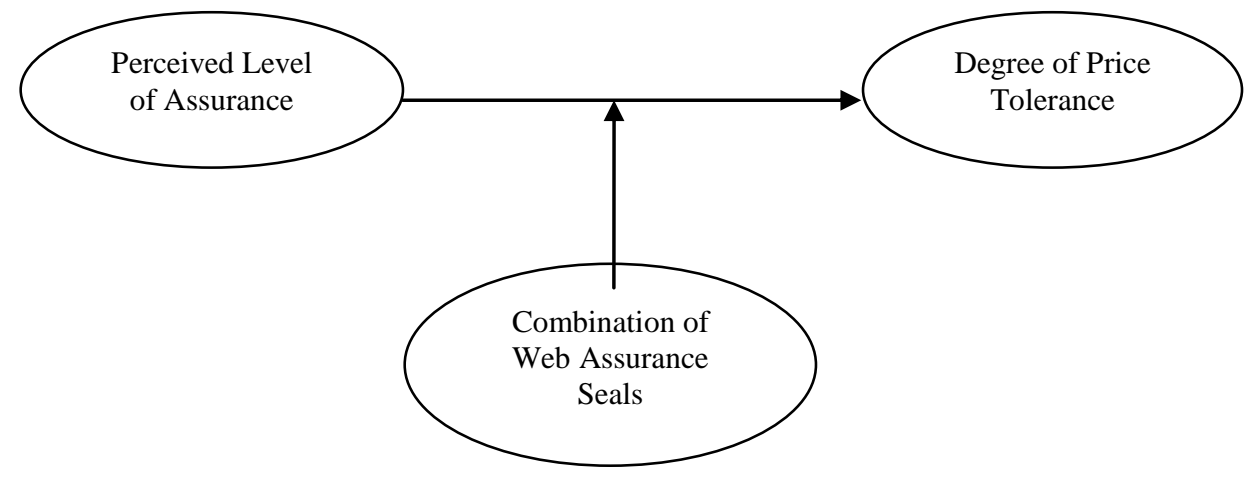

It would be intriguing to test if CPA-seals could contribute to a higher price subjects were willing to pay. For this test, extra materials were built into the survey, and as part of the survey, a significant amount of data was 
collected. This test took the same approach as that used in the test of $\mathrm{H} 2$ because of similarity of the two cases. Again, because of the scarce relationship between level of assurance and maximum price, statistical test of moderation was not warranted; only descriptive analysis was conducted. The comparison was made between 2, 4, and 6 non-CPA seals and the same number of seals that had half CPA seals and half non-CPA seals; the differences in maximum-price subjects were willing to pay were as in Table 8.

Table 8: Descriptive Comparison(Additional Test)

\begin{tabular}{|c|c|c|c|c|}
\hline No. of Seals & Non-CPA Seals Only & CPA \& Non-CPA Seals & Difference in \$ & Difference in \% \\
\hline 2 & 43 & 53 & $\$ 10$ & $23.2 \%$ \\
\hline 4 & 54 & 57 & $\$ 3$ & $5.5 \%$ \\
\hline 6 & 51 & 57 & $\$ 6$ & $11.8 \%$ \\
\hline
\end{tabular}

* Values of maximum-price were taken by averaging.

The difference in terms of dollar amount and the difference in terms of percentage were both substantially different between the groups. The highest difference was as much as $\$ 10$ or 23.2 percent; that was when the number of seals displayed was two. By this result, the additional test question was answered with that CPA-associated seals had a considerable positive effect on the price that student-subjects were willing to pay.

\section{Additional Finding}

Table 9: Summary of Additional Finding

\begin{tabular}{|l|l|c|c|}
\hline & \multicolumn{1}{|c|}{ Web Assurance Seals } & \% Seen Ever & $\begin{array}{c}\text { \% Recognized as CPA- } \\
\text { Associated }\end{array}$ \\
\hline CPA-Associated & SysTrust & $\mathbf{2 0 . 2}$ & 32.1 \\
\hline & WebTrust & 10.9 & 25.5 \\
\hline Non-CPA-Associated & BETTERWEB & 6 & 24.8 \\
\hline & VeriSign & 49.7 & 39.1 \\
\hline & TRUSTe & 44.7 & 46.4 \\
\hline & BBB Privacy & 11.9 & 30.5 \\
\hline & BBB Reliability & 11.3 & 21.2 \\
\hline & Good Housekeeping & 9.3 & 13.9 \\
\hline & Geo Trust & 6.3 & 17.2 \\
\hline
\end{tabular}

As shown in Table 9, the examples of CPA-associated seals were not well known to subjects as much as the top two most popular non-CPA seals. If all the seals were placed in the order of familiarity, CPA-associated seals would be placed third, sixth, and ninth among nine seals. On the other hand, when subjects were asked which seals were associated with accounting institutions, high percentages (39.1 percent and 46.4 percent) of them thought that the two best-known non-CPA seals (VeriSign and TRUSTe) were related to the accounting profession. Another point of interest is that only 6 percent of subjects have seen BetterWeb, but about 25 percent of them correctly recognized it as a CPA-related seal. One obvious reason for it is that the full name of the company that created the seal was included in the seal. Around one fourth to one third of subjects could tell CPA seals from non-CPA seals. Overall, as of the time of data collection, it seemed that VeriSign and TRUSTe were the leaders in the web assurance seal market.

\section{DISCUSSION, CONCLUSION, AND LIMITATIONS}

The survey result indicates that about one third of the subject pool felt an increased risk in B2C online transactions over the previous year. This perception then translated to their online shopping behavior in an amplified fashion. The absolute majority of them (88\%) have never or rarely shopped on a web site they are not familiar with. This trend was found true even when they came across a favorable deal, until they established a base of trustworthiness with the unknown site. Web assurance seals by themselves had marginally positive effects on perceived online trust; meanwhile, CPA-related seals produced relatively higher positive effects than their counterparts. This tendency still held true even when multiple seals were exhibited. Regarding the relationship between assurance level and price level, there was nearly no connection between them in the proposed context. Nevertheless, CPA seals showed significant potential that they could encourage tolerance of higher prices than nonCPA seals. 
In conclusion, while online consumers were very sensitive to trust issues, web assurance seals served the purpose for which they were created only to a very limited degree. The degree of familiarity of assurance seals among people varied from known-to-most-people to only-to-a-handful-of-people. The high side of the findings is that CPA seals had considerable potential to be recognized higher and support higher product prices than average non-CPA seals. Considering the fact that a very low percentage of people can differentiate CPA-associated seals from non-CPA-associated seals, CPA-associated seal providers need to find a way to promote themselves and their seals. Embedding seal-provider's initials, logo, or name within the seal can be one of the potential approaches.

As for limitations of the study, readers should note that the subjects in this study are students with limited generalizability. Second, previous literature suggests that intentions are not always realized in actual behaviors. However, we believe it provides a solid framework and sets the stage to build upon for further research. Future studies might want to explore other factors such as a creative graphic image, clear wording, excellent exhibition of product, ease of navigation within the website, etc. Whether the hypotheses were supported or not, the results of the study brought out practical, relevant outcomes on the effectiveness of web assurance seals and one synergy effect of the seals on price. Having this reasoning in mind, readers of this study should comprehend the findings and implications of the current study.

\section{AUTHOR INFORMATION}

Dr. Seung Hwan Kim is originally from South Korea. He received his bachelor's degree in international business from Dankook University in his home country. Since 1993, he has been living in the United States and got master's and doctorate in accounting in 1999 and 2008, respectively, both from Southern Illinois University Carbondale. He currently teaches accounting at Indiana University of Pennsylvania beginning fall semester 2012. His main research interests lie in e-commerce, accounting information systems, and accounting education. Seung Hwan Kim, Ph.D., Associate Professor of Accounting, Indiana University of Pennsylvania, USA. E-mail: seung.kim@iup.edu

\section{REFERENCES}

1. Bellman, Steven, Lohse, Gerald L., and Johnson, Eric J. (1999). Predictors of Online Buying Behavior. Communications of the ACM, 42(12), 32-38.

2. Berendt, Bettina, Günther, Oliver, and Spiekermann, Sarah (2005). Privacy in E-Commerce: Stated Preferences vs. Actual Behavior. Communications of the ACM, 48(4), 101-106.

3. Gefen, D., Karahanna, E., and Straub, D. (2003). Trust and TAM in Online Shopping: An Integrated Model Source. MIS Quarterly, 27(1), 51-90.

4. Hu, X., Wu, G., Wu, Y., and Zhang, H. (2010). The Effects of Web Assurance Seals on Consumers' Initial Trust in an Online Vendor: A Functional Perspective. Decision Support Systems, 48, 407-418.

5. Kaplan, S.E. and Nieschwietz R.J. (2003). A Web Assurance Services Model of Trust for B2C ECommerce. International Journal of Accounting Information Systems, 4, 95-114.

6. Kim, K. and Prabhakar, B. (2004). Initial Trust and the Adoption of B2C E-Commerce: The Case of Internet Banking. Database, 35(2), 50-64.

7. Kovar, S.E., Burke, K.G., and Kovar, B.R. (2000). Consumer Responses to the CPA WebTrust Assurance. Journal of Information Systems, 14, 17-35.

8. McKnight, D., Choudhury, V., and Kacmar, C. (2002). Developing and Validating Trust Measures for ECommerce: An Integrative Typology. Information Systems Research, 13(3), 334-359.

9. Mauldin, E., and Arunachalam V. (2002). An Experimental Examination of Alternative Forms of Web Assurance for Business-to-Consumer E-Commerce. Journal of Information Systems, 16(1), 33-54.

10. Moores, T. (2005). Do Consumers Understand the Role of Privacy Seals in E-Commerce? Communications of the ACM, 48(3), 86--91.

11. Mutz, D.C. (2005). Social Trust and E-Commerce; Experimental Evidence for the Effects of Social Trust on Individuals' Economic Behavior. Public Opinion Quarterly, 69(3), 393-416.

12. Odom, M.D., Kumar, A., and Saunders, L. (2002). Web Assurance Seals: How and Why They Influence Consumers' Decisions. Journal of Information Systems, 16, 231-250.

13. Ratnasingam, P. (2005). E-Commerce Relationships: The Impact of Trust on Relationship Continuity. International Journal of Commerce \& Management, 15(1), 1-16. 
14. Salam, A. F., Iyer, L., Palvia, P., and Singh, R. (2005). Trust, Technology Usage and Exchange

Relationship in E-Commerce: A Comprehensive Framework. Communications of the ACM, 48(2), 73--77.

15. Shankar, V., Urban, G., and Sultan, F. (2002). Online Trust: A Stakeholder Perspective, Concepts, Implications, and Future Directions. Journal of Strategic Information Systems, 11(1), 325-344.

16. Wakefield, R.J., Stocks, M.H., and Wilder, W.M. (2004). The Role of Web Site Characteristics in Initial Trust Formation. Journal of Computer Information Systems, 45(1), 94-103. 


\section{NOTES}

